\title{
The Utilization of Cold-water Zooplankton as Prey for Chum Salmon Fry in Yamada Bay, Iwate, Pacific Coast of Northern Japan
}

\author{
Yuichiro Yamada ${ }^{1}$, Kei Sasaki ${ }^{2}$, Kodai Yamane ${ }^{3}$, Miwa Yatsuya², Yuichi Shimizu ${ }^{4}$, Yoshitomo Nagakura ${ }^{2}$, \\ Tadahide Kurokawa ${ }^{5}$, and Hideki Nikaido ${ }^{2}$
}

${ }^{1}$ School of Marine Biosciences, Kitasato University, Sagamihara, 252-0373, Japan

${ }^{2}$ Tohoku National Fisheries Research Institute, Miyako, 027-0097, Japan

${ }^{3}$ Iwate Prefectural Agriculture, Forestry and Fisheries Department, Morioka, 020-8570, Japan

${ }^{4}$ Iwate Fisheries Technology Center, Kamaishi, 026-0001, Japan

${ }^{5}$ Hokkaido National Fisheries Research Institute, Kushiro, 085-0802, Japan

Keywords: chum salmon fry, feeding habits, food environment, zooplankton, Neocalanus plumchrus, Themisto japonica, Oyashio

After migrating into the sea from rivers, chum salmon fry stay in coastal areas during spring to early summer, subsequently migrating to the northern North Pacific Ocean (Seki 2005). The availability of prey organisms in this early marine period is one of the most important factors affecting growth and survival of salmon fry (Terazaki and Iwata 1983; Ban et al. 1996; Seki 2005). The magnitude of the Oyashio Current significantly affects the zooplankton community structure in nearshore waters during this period (Terazaki 1980; Kotani et al. 1988; Nishibe et al. 2016). Therefore, we expect that feeding habits and prey selectivity of chum fry might vary in response to fluctuations in coastal environmental conditions. In order to clarify these relationships, we analyzed the stomach contents composition of chum salmon fry and in situ zooplankton community structure during their coastal residence period using samples collected at the Sanriku coastal area for four years. Our ultimate goal is to clarify the relationship between the nearshore environment of chum fry and the adult return rate, and to subsequently develop a salmon fry release strategy to improve returns of adult salmon.

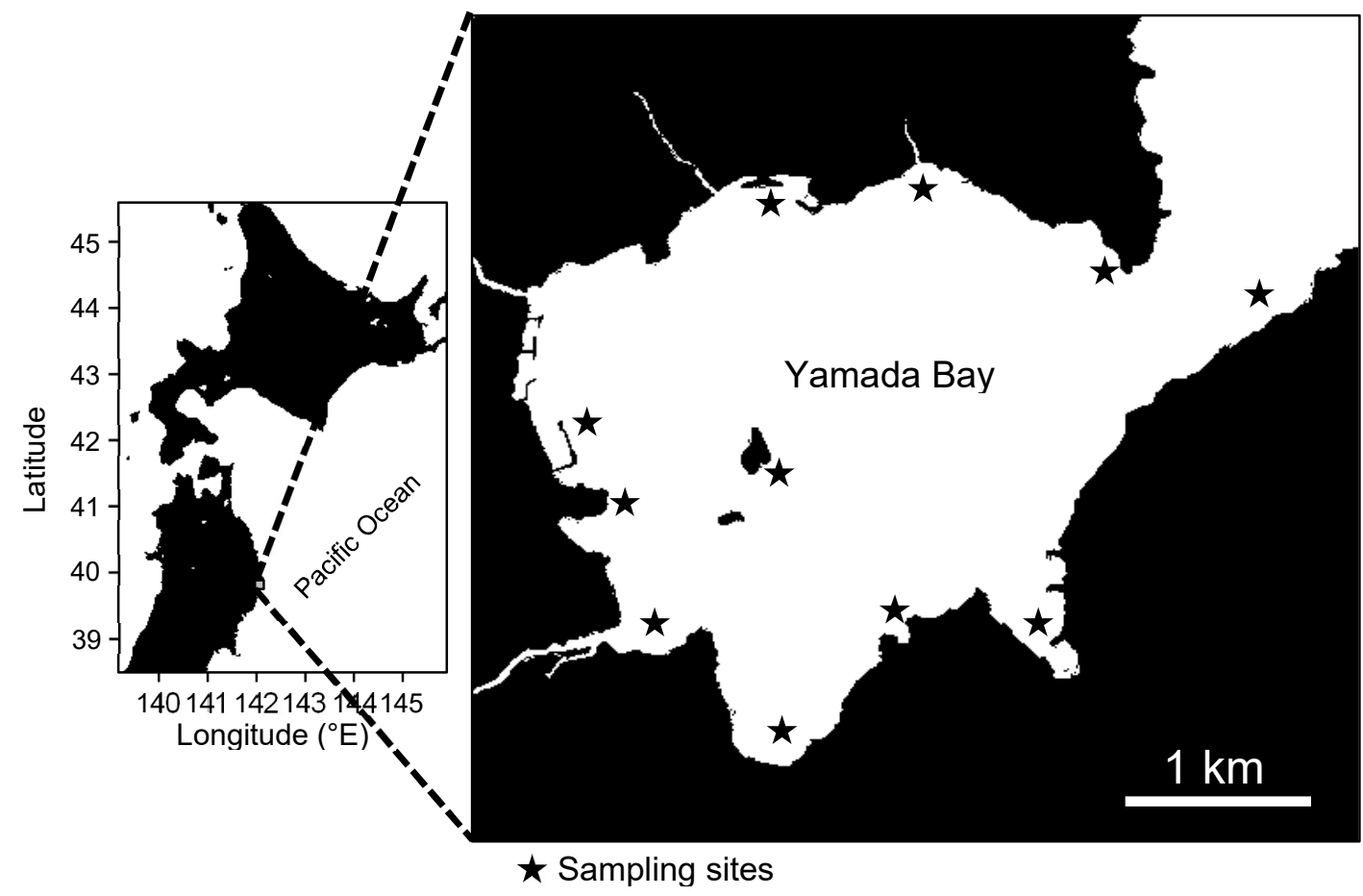

Fig. 1.

Station and date of sampling from 2013 to 2016 in Yamada Bay.

We collected 1,252 salmon fry over a four-year period (2013-2016) at 12 sampling sites in Yamada Bay (Fig. 1) using a purse seine. At the time that we collected the fry, we also collected zooplankton samples using a surface plankton net (mouth diameter $30 \mathrm{~cm}$, mesh size $0.33 \mathrm{~mm}$ ). We dissected preserved stomachs to remove their contents and all ingested organisms were counted and identified into 17 different taxa. We measured wet weight for

All correspondence should be addressed to Y. Yamada. 
each taxon identified to $0.01 \mathrm{mg}$ with an electronic balance. Zooplankton samples were also identified into 17 taxonomic groups, and the total wet weight of each taxonomic group was measured using the same methods we used with stomach contents.

\section{A}
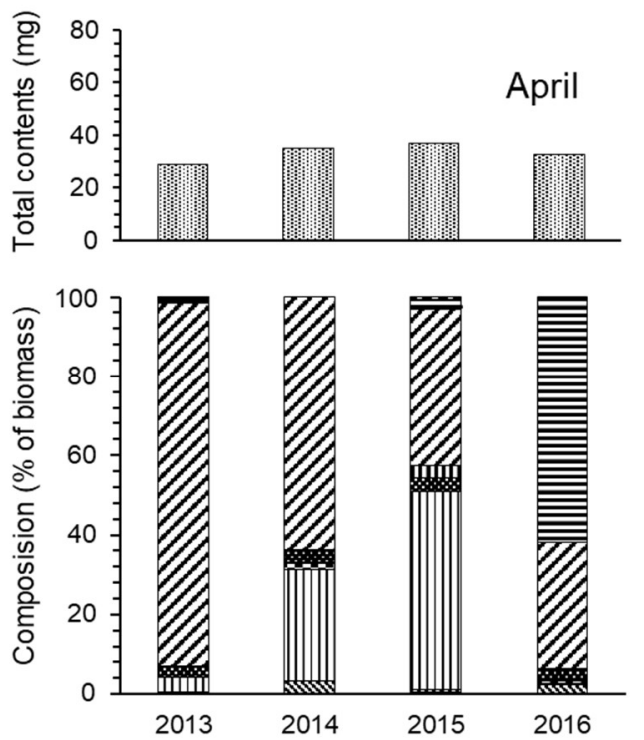

\begin{tabular}{|c|c|c|c|}
\hline $\begin{array}{l}\text { Acartia spp. } \\
\text { Eucalanus bungii }\end{array}$ & Pseudocalanusspp. & - Centropagesspp. & $\begin{array}{l}\text { (1) Neocalanus plunchrus } \\
\text { II Harpacticoids }\end{array}$ \\
\hline G Themisto japonica & 9 Gammarids & 目 Cumacean & 目 Decapod larvae \\
\hline $\begin{array}{l}\text { E Barnacle larvae } \\
\text { Cladocera }\end{array}$ & Cnidarian & 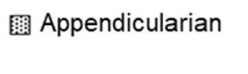 & $\mathbf{\nabla}$ Insects \\
\hline
\end{tabular}

\section{B}
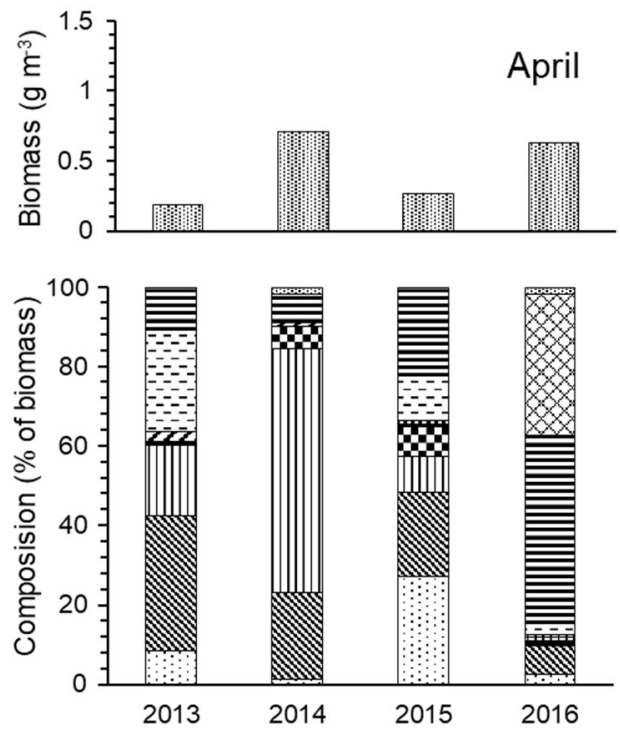
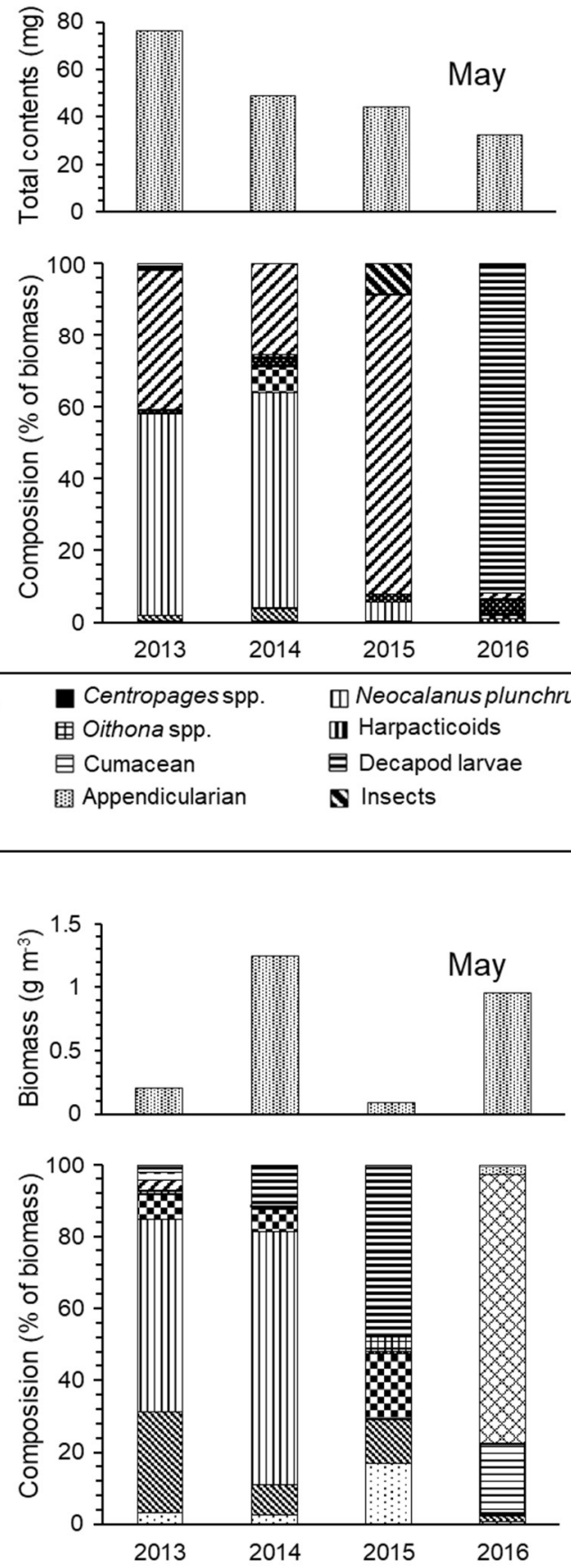

Fig. 2. Yearly comparison in stomach content composition of chum salmon fry (A) and environmental zooplankton community (B) in April and May. Total contents (upper panel) and percentage composition of each taxon group (lower panel) were shown by gravimetric terms.

The mean water temperatures during the study period were low in 2013 and $2014\left(8.3\right.$ and $6.7^{\circ} \mathrm{C}$, respectively), and high in 2015 and $2016\left(9.4\right.$ and $11.1^{\circ} \mathrm{C}$, respectively). In particular, the water temperature was extremely high in 2016 throughout the study period $\left(\min ; 9.2^{\circ} \mathrm{C}\right.$, $\left.\max ; 14.5^{\circ} \mathrm{C}\right)$. 
Neocalanus plumchrus (copepod) and Themisto japonica (amphipod) are typical cold-water zooplankton that dominated the stomach contents of chum fry, except for 2016 (Fig. 2A); however, these zooplankton were not necessarily the most dominant in the water column (Fig. 2B). In 2016, zooplankton communities in the water column were mostly dominated by cnidarians and decapod larvae, and chum fry preyed primarily on decapod larvae (Fig. 2B). Based on the results of stomach content composition of chum fry and field zooplankton community structure, we calculated Ivlev's elective values (EV, Ivlev 1961). The EV for Themisto japonica and Neocalanus plumchrus was always positive, suggesting that chum fry selectively preyed upon these cold-water zooplankters (Fig. 3). Decapod larvae were hardly preyed upon during 2013 to 2015; however, they were markedly preyed upon in 2016. Among small copepods, the $E V$ for Acartia spp. and Pseudocalanus spp. were always negative, whereas the $E V$ for harpacticoids was always positive.

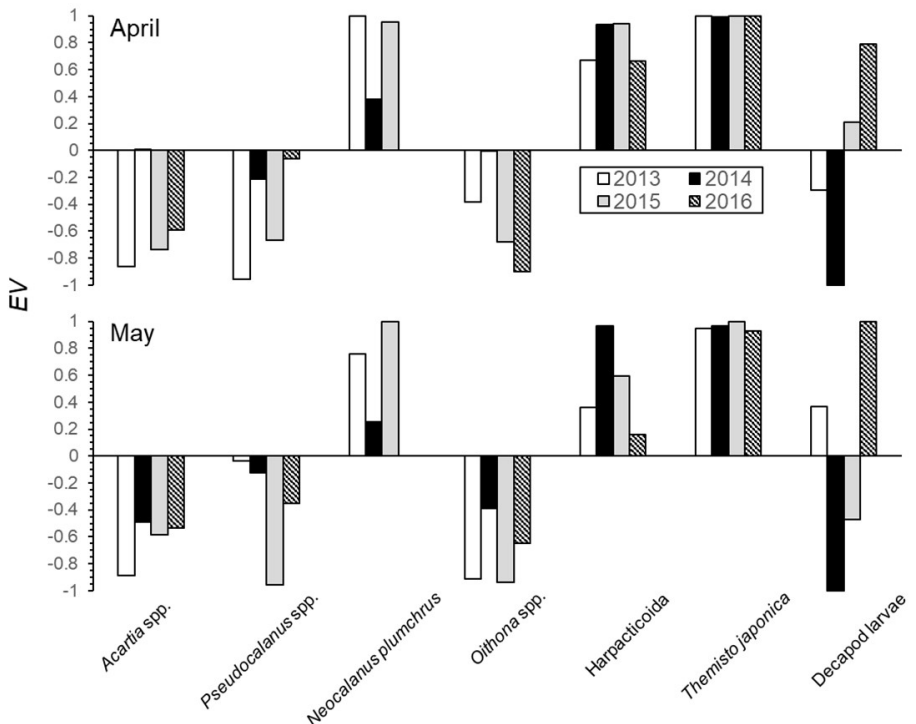

Fig. 3. Elective values $(E V)$ of chum salmon fry for seven major taxonomic groups during 2013 to 2016.

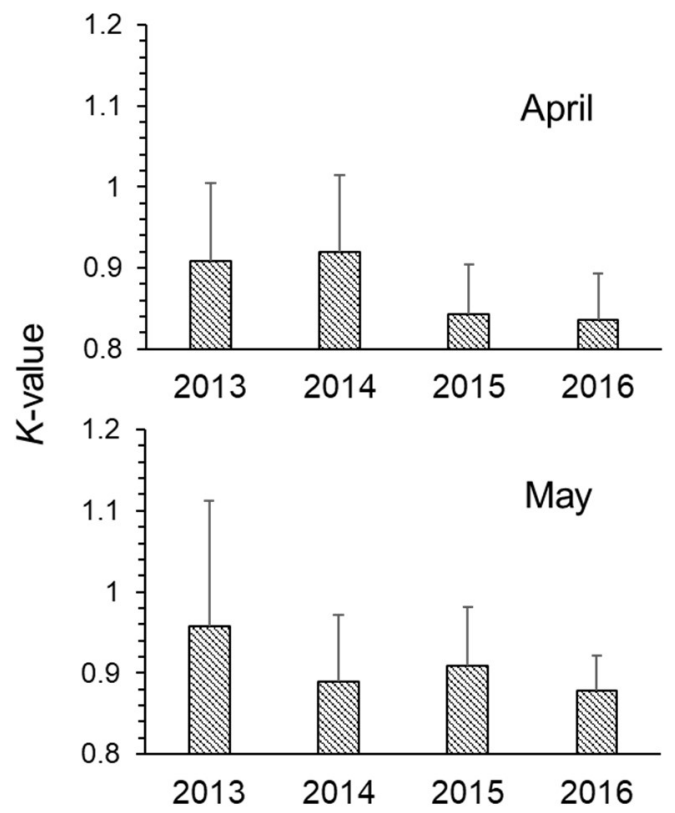

Condition factor ( $K$-value), as an indicator of somatic nutritional status for chum fry (Azuma et al. 1998) were higher in cold-water years than those of warm-water years (Fig. 4). Because these two cold-water zooplankton species are typically abundant in the Oyashio Current, the magnitude of Oyashio inflow into the coastal area may affect prey availability for chum salmon fry and their nutritional status. 
Table 1. Comparisons of mean water temperature and mean biomass of cold-water zooplankters (Neocalanus plumchrus + Themisto japonica) in the water column of each study period, and adult return rate after three years in the entire coastal area of Iwate Prefecture.

\begin{tabular}{cccc}
\hline $\begin{array}{c}\text { Costal retention } \\
\text { year }\end{array}$ & $\begin{array}{c}\text { Mean water } \\
\text { temp. }\left({ }^{\circ} \mathrm{C}\right)\end{array}$ & $\begin{array}{c}\text { Neocalanus }+ \text { Themisto } \\
\text { biomass }\left(\mathrm{mg} \mathrm{m}^{-3}\right)\end{array}$ & $\begin{array}{c}\text { Adult return rate after 3 } \\
\text { years }(\%)\end{array}$ \\
\hline 2013 & 8.3 & 98.5 & 0.9 \\
2014 & 6.7 & 606.9 & 0.6 \\
2015 & 9.4 & 10.7 & 0.9 \\
2016 & 11.1 & 0.5 & 0.2 \\
\hline
\end{tabular}

The adult return rate of chum salmon that spent their fry period during this study varied from 0.6 to $0.9 \%$ between 2016 and 2018, with an extremely low value (0.2\%) in 2019 (Table 1). Most of the adults returning in 2019 spent their coastal residence period in 2016 when cold water zooplanktons were very low. These results suggest that food availability during the coastal retention period affects the survival rate of salmon fry, and is one of the important factors influencing the return rate of adult salmon. Detailed studies are needed to elucidate the relationship between environmental conditions during the coastal residence periods and the adult return rates.

\section{REFERENCES}

Azuma, T., T. Yada, Y. Ueno, and M. Iwata. 1998. Biochemical approach to assessing growth characteristics in salmonids. N. Pac. Anadr. Fish Comm. Bull. 1: 103-111. (Available at https://npafc.org)

Ban, M., H. Hasegawa, M. Ezure. 1996. Effects of starvation and refeeding on physiological condition of juvenile chum salmon Oncorhynchus keta. Sci. Rep. Hokkaido Salmon Hatchery 50: 117-123. (In Japanese with English Abstract)

Ivlev, I. 1961. Experimental Ecology of the Feeding of Fish. Yale Univ. Press, New Heaven. 302 pp.

Kotani, Y., K. Odate, Y. Ueno, and K. Ishida. 1988. Some variations in zooplankton biomass in the waters off the coast of Sanriku, Northeastern Japan. Bull. Tohoku Reg. Fish. Res. Lab. 50: 125-131. (In Japanese with English abstract)

Nishibe, Y., H. Isami, H. Fukuda, S. Nishida, T. Nagata, A. Tachibana, and A. Tsuda. 2016. Impact of the 2011 Tohoku earthquake tsunami on zooplankton community in Otsuchi Bay, northeastern Japan. J. Oceanogr. 72: 77-90.

Seki, J. 2005. Study of characteristic of feeding habitat of juvenile chum salmon and their food environment in the Pacific coastal waters, central part of Hokkaido. Bull. Nat. Salmon Resources Center 7: 1-104. (In Japanese with English Abstract)

Terazaki, M. 1980. Zooplankton in Otuschi Bay. Otsuchi Mar. Res. Cent. Rep. 6: 1-6. (In Japanese with English Abstract)

Terazaki, M., and M. Iwata. 1983. Feeding habits of chum salmon Oncorhynchus keta collected from Otsuchi Bay. Nippon Suisan Gakkaishi 49: 1187-1193. 